\title{
IMPLEMENTACIÓN DE UNA ESTRATEGIA DE CONCIENTIZACIÓN DE LOS RIESGOS EN BOGOTÁ PARA LA POBLACIÓN ADOLESCENTE ${ }^{1}$
}

\section{A risk awareness strategy implementation for youth people in Bogota}

\author{
Natalia Romero Romero ${ }^{2}$ \\ Institución Universitaria Politécnico Grancolombiano \\ Colombia \\ Diana Estrada Quintero 3 \\ Institución Universitaria Politécnico Grancolombiano \\ Colombia \\ Hugo Armando Guzmán Useche ${ }^{4}$ \\ Institución Universitaria Politécnico Grancolombiano \\ Colombia
}

\begin{abstract}
Resumen
En ocasiones las condiciones de los contratos de seguros son de difícil comprensión y, en consecuencia, los individuos creen que asegurar su vida y la de su familia, así como proteger sus propiedades (como la vivienda) no es necesario, esta percepción del riesgo afecta el desempeño del sector asegurador (García, 2013).

De ahí que sea preciso entender y crear conciencia sobre los riesgos a los que está diariamente expuesta una ciudad como Bogotá, y otorgar al tema la importancia que requiere. Pero este entendimiento es una responsabilidad de todos y, para ello, se debe pensar en una formación sobre riesgos enfocada en los adolescentes entre los 15 y 17 años. La presente investigación se centra en esta población por dos razones: la primera, porque es necesario que a esta edad exista un grado de madurez y responsabilidad mayor para asumir y asimilar la información que van a recibir y, la segunda, porque son personas que están a punto de terminar su bachillerato y empezaran a tomar sus propias decisiones sobre su vida, por ello, se busca que la determinación de cuidar su vida y su patrimonio sea un aspecto primordial.

El estudio ejecutó un ejercicio estadístico sobre los diferentes eventos a nivel de riesgos que se han presentado en la ciudad de Bogotá, con el fin de entender su impacto, severidad y consecuencias en la sociedad. Posteriormente, se argumentó la importancia de los seguros desde un punto de
\end{abstract}

\footnotetext{
${ }^{1}$ Cite este artículo como: Romero-Romero, D., Estrada-Quintero, D., Guzmán Useche, H. Implementación de una estrategia de concientización de los riesgos en Bogotá para la población adolescente. Revista Punto de Vista, 12 (17), pp. 85-106.

${ }^{2}$ Especialista en gerencia de riesgos y seguros de la Institución Universitaria Politécnico Grancolombiano. Correo electrónico: naromero9@poligran.edu.co.

${ }^{3}$ Especialista en gerencia de riesgos y seguros de la Institución Universitaria Politécnico Grancolombiano. Correo electrónico: diestrada1@poligran.edu.co

${ }^{4}$ Máster universitario en seguros y gerencia de riesgos de la Universidad Pontificia de Salamanca, Magíster en Marketing digital de la UNIR, Especialista en Alta Dirección de seguros de la EAN, Especialista en Gerencia de proyectos de Ingeniería de la EAN e ingeniero mecánico. Profesor Asociado de la Institución Universitaria Politécnico Grancolombiano. Correo electrónico: haguzmanu@poligran.edu.co
} 
vista cultural y de inversión y se evaluaron las opiniones de esos adolescentes al respecto mediante encuesta. Este proceso se complementó con la técnica de entrevista a un líder del sector asegurador. Los resultados sirvieron de base para presentar una propuesta sobre un Programa de identificación, clasificación y prevención de riesgos pensada para los estudiantes de $10^{\circ}$ y $11^{\circ}$.

Palabras clave:

Riesgos; Educación; Seguros; Patrimonio; Catástrofe; Mitigar; Adolescencia.

\begin{abstract}
Sometimes the conditions of insurance contracts are difficult to understand and, consequently, individuals believe that insuring their life and that of their family, as well as protecting their properties (such as housing) is not necessary, this perception of risk affects the performance of the insurance sector (García, 2013).

Hence, it is necessary to understand and create awareness about the risks to which a city like Bogotá is exposed daily and give the issue the importance it requires. But this understanding is everyone's responsibility and, for this, a risk training focused on adolescents between 15 and 17 years should be considered. The present research focuses on this population for two reasons: the first, because it is necessary that at this age there is a greater degree of maturity and responsibility to assume and assimilate the information they are going to receive and, the second, because they are people who are about to finish their high school and they will begin to make their own decisions about their life and, therefore, it is sought that the determination to take care of their life and their heritage is a fundamental aspect.

The study carried out a statistical exercise on the different events at the risk level that have occurred in the city of Bogotá, in order to understand their impact, severity and consequences on society. Subsequently, the importance of insurance from a cultural and investment point of view was argued and the opinions of these adolescents in this regard were evaluated through a survey. This process was complemented with the technique of interviewing a leader in the insurance sector. The results served as the basis for presenting a proposal for a risk identification, classification and prevention program designed for 10th and 11th grade students.
\end{abstract}

$\begin{array}{ll}\text { Recepción: } & \mathbf{2 1 . 0 7 . 2 0 2 0} \\ \text { Aceptación: } & \mathbf{0 1 . 1 1 . 2 0 2 0}\end{array}$

\title{
INTRODUCCIÓN
}

La observación de riesgos y seguros es importante debido a la compresión y concientización que la sociedad bogotana puede adquirir desde la adolescencia sobre los riesgos naturales, materiales y de personas a los cuales está expuesta durante la vida y en todo momento, sin necesidad de pertenecer al gremio asegurador, logrando así que el ciudadano bogotano comprenda que el seguro debe hacer parte de su cultura y, para el asegurador, una oportunidad de aumentar la venta de seguros desde el entendimiento y razón de ser de los mismos: como una solución en caso de materializarse el riesgo. Sin ánimo de profundizar, o tocar el tema de los seguros a fondo, ¿Podría la formación en riesgos desde temprana edad, cambiar la óptica que la sociedad bogotana tiene con respecto a asegurar su vida y sus bienes? 
Si hoy surgiera la pregunta ¿En Colombia existe un compromiso por parte de todos los estamentos institucionales para enfrentar las ocurrencias de eventos catastróficos que amenazan la estabilidad económica, social y política del país? ¿Cuál sería la respuesta? ¿Por qué Bogotá, una ciudad tan vulnerable y con una historia amplia y profunda de violencia, desastres naturales y orden público, no es educada, al menos, con respecto a estos riesgos?

Mediante un recorrido estadístico, que tiene como propósito sensibilizar en relación con la realidad de la ciudad de Bogotá y un análisis de los riesgos más impactantes, se demuestra la necesidad e importancia de concientizar y educar desde temprana edad a los estudiantes sobre los riesgos a los cuales está expuesta la sociedad bogotana. Se busca brindan una oportunidad al ente regulador en materia educativa de la capital, para revisar la viabilidad de aprobar esta propuesta e incluirla en un pénsum académico de básica secundaria.

Si bien el gobierno ya viene trabajando en proyectos y programas para la atención de emergencias y desastres naturales, en éstos no incluyen una participación directa y activa de los jóvenes, es por lo que, por medio de este artículo, se realiza un llamado de atención a los responsables de la educación en Colombia, para no lamentar no haber tomado decisiones que permitieran fortalecer la protección de la población, cuando se materialice un riesgo.

Tal vez algunos escépticos no conciban la idea de involucrar a estudiantes de grado $10^{\circ}$ y $11^{\circ}$ de la capital para formarse, desde las aulas escolares, en temas de riesgos, y concientizarlos sobre su importancia, mucho menos hacerlos partícipes de los programas que ya vienen adelantando las organizaciones gubernamentales pues consideran que las personas que están directamente relacionadas con los conceptos de desastres naturales, emergencias, planes de evacuación, son las compañías aseguradoras.

Ese letargo tal vez se asocie a que no se han visto afectados directamente por los peligros a los que puedan verse expuestos y, por tanto, no dimensionan la importancia de concebir el poder atender desde su propia cotidianidad, activamente, situaciones de peligro que atenten contra ellos.

\section{MÉTODO}

Para atender a la necesidad de formación y concientización sobre riesgos este artículo de investigación ejecuta un análisis de tipo mixto que usa el recurso de la investigación-acción educativa y contempla 3 partes: un análisis estadístico, un estudio de la población y el entorno y unas intervenciones. A continuación, se presentan las actividades que se ejecutaron en cada uno de ellos:

Análisis Estadístico

- Se hizo una recopilación de los indicares estadísticos a nivel de riesgos en Bogotá, para identificar el nivel de importancia según las pérdidas ocasionadas, el estudio se basó en los reportes del IDIGER y fue de carácter descriptivo.

Población y Entorno

En esta sección se hace un estudio que va dirigido a:

- Ente regulador de la educación en Colombia.

- Directores y docentes responsables de la educación para básica secundaria en Bogotá.

- Organizaciones de atención y prevención de desastres.

- Gremio asegurador.

- Padres de familia de estudiantes básica secundaria. 
Intervenciones

- Por medio de una recolección documental se justificó la importancia de los seguros bajo una percepción cultural y de inversión, y no material y de gasto.

- Posteriormente se realizó una entrevista al Gerente de Riesgos de Liberty Seguros, Camilo Goez.

- Se aplicó una encuesta a los estudiantes del grado $10^{\circ}$ y $11^{\circ}$ de un colegio privado en la ciudad de Bogotá.

- Se aplicó una encuesta a los estudiantes del grado $10^{\circ}$ y $11^{\circ}$ de un Colegio público en la ciudad de Bogotá.

- Se elaboró una propuesta sobre un programa de identificación, clasificación y prevención de riesgos pensada en los estudiantes de $10^{\circ}$ y $11^{\circ}$.

\section{RESULTADOS}

\section{Contexto estadístico}

Los desastres ocasionan efectos adversos directos como las pérdidas de vidas, heridos, pérdida de bienes y servicios, disminución del patrimonio, por citar algunas; también presentan pérdidas indirectas, haciendo referencias a los efectos adversos derivados de esas pérdidas directas, como los efectos en el comercio y la industria, la desmotivación de la inversión, entre otras (Glosario de términos, siglas y abreviaturas al Plan Nacional de Emergencia Guaymura, 1992, p. 29). De ahí que no sea posible estar ajenos a estas calamidades, y mucho menos señalar solo a un grupo de personas responsables de alguna manera de estos hechos. Pues recordamos que la materialización del riesgo es más que una amenaza, no es predecible ni tampoco está determinado por el estatus que ocupa la persona en la sociedad, así que compete a todos los ciudadanos asumir una responsabilidad continua frente al tema.

Para contextualizar algunas cifras, es oportuno referenciar los escenarios de riesgos de mayor impacto en Bogotá, presentados por el Instituto Distrital de Gestión de Riesgos y Cambio Climático (IDIGER), entidad que coordina, orienta y consolida el Sistema Distrital de Gestión de Riesgos y Cambio Climático - SDGR -CC en la capital del país:

Riesgos por Aglomeraciones de Público:

Este tipo de riesgos se relaciona con el conjunto de personas reunidas en un mismo lugar, que se presentan principalmente por espectáculos públicos, eventos deportivos, congregaciones religiosas y políticas, destacando a continuación los eventos más significativos en los últimos 15 años ocurridos en este tipo de riesgos en Bogotá:

\begin{tabular}{|llll|}
\hline AÑO & LUGAR & EVENTO & VICTIMAS \\
\hline $\mathbf{2 0 0 1}$ & Parque EI Tunal & Concierto. Estampida & 1 muerto y 145 heridos \\
$\mathbf{2 0 0 2}$ & Parque Simón Bolívar & Festival de Verano. Ahogamiento & 3 muertos \\
\hline $\mathbf{2 0 0 3}$ & Coliseo El Campin & Evento Religioso. Estampida & 35 heridos \\
$\mathbf{2 0 0 5}$ & Estadio El Campin & Enfrentamiento hinchas & 1 muerto y 24 heridos \\
$\mathbf{2 0 0 5}$ & Plaza de Bolívar & Comparsas. Falla de los filtros & 4 heridos \\
$\mathbf{2 0 1 0}$ & Plaza de Bolívar & 20 de Julio - Salidas obstruidas & 20 heridos \\
$\mathbf{2 0 1 1}$ & Coliseo El Campín & Falla en Filtros y cerramiento & 40 heridos \\
& & especial & \\
\hline
\end{tabular}

Tabla 1. Últimos eventos por aglomeración. Nota: Recuperado del Decreto Nacional 3888 de 2007. IDIGER.

Según el análisis realizado por el IDIGER (2017), para el año 2015 la participación de la población bogotana en eventos clasificados como de alta complejidad varía significativamente en periodos de tiempo, sin embargo, sería 
suficiente si en uno de éstos se desencadenan estampidas humanas o comportamientos reprochables de los asistentes, sin contar con la posibilidad de ocurrencias de fenómenos naturales como sismos, tormentas eléctricas, lluvias torrenciales, entre otros; o, quizás, de origen tecnológico como cortos circuitos, incendios y explosiones, sin contar con la posibilidad de actos terroristas, situaciones todas que pueden generar en los asistentes un verdadero caos, pánico y conductas impulsivas no controladas que deriven en heridos y muertos.

De acuerdo con lo mencionado, la gráfica presentada a continuación representa la variabilidad de los asistentes a este tipo de eventos.

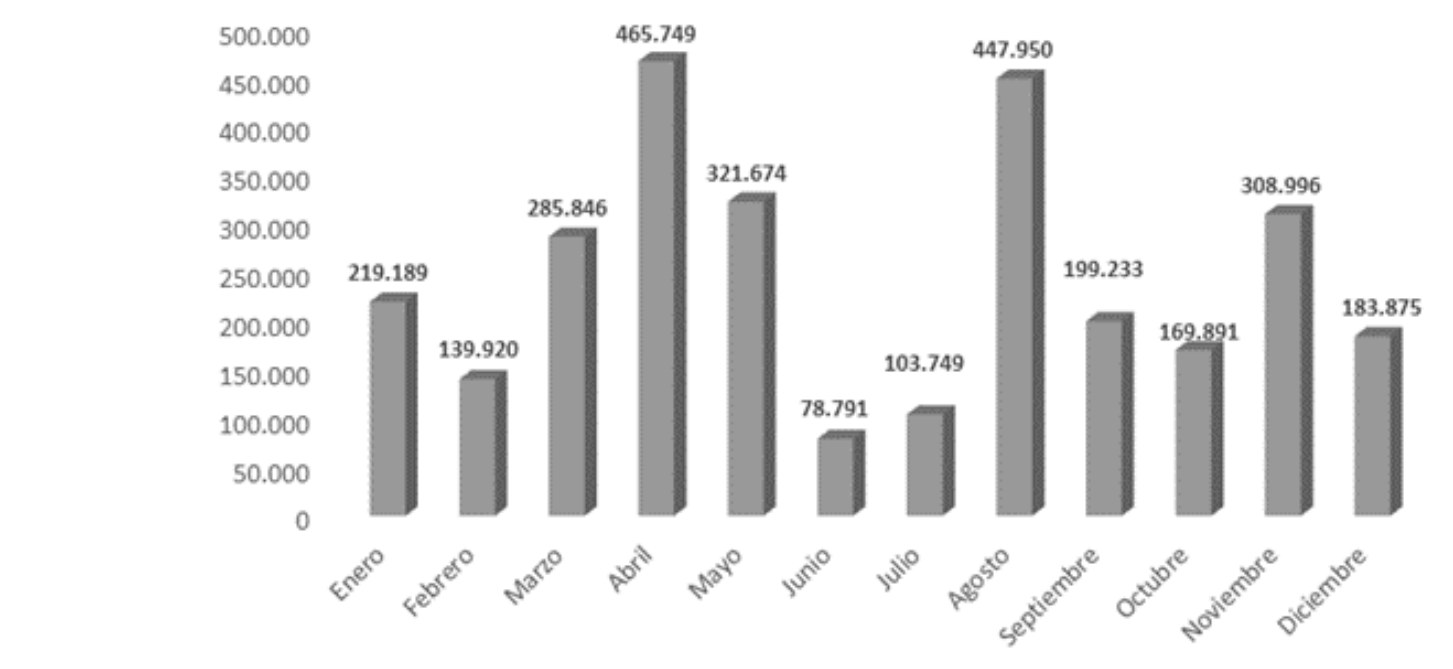

Gráfico 1. Asistentes a eventos de alta complejidad en 2015. Nota: Recuperado de: Instituto Distrital de Gestión de Riesgos y Cambio Climático. IDIGER (5 de Diciembre de 2017) http://www.idiger.gov.co/riesgo-por-aglomeraciones-de-publico

\section{Riesgo por construcción de edificaciones}

El riesgo por construcción de edificaciones se entiende como un fenómeno de origen antrópico, asociado a los procesos o dinámicas inducidas por actividades propias de la cadena de la construcción.

En Bogotá, entre los años 2011 a 2016 el IDIGER atendió, bien sea por solicitud de la comunidad o por ocasión de eventos de emergencia registrados en la "línea 123 " condiciones clasificadas como de Riesgo estructural; así mismo, se han atendido 767 visitas de verificación de condiciones que amenazan ruina, en los que se registraron alrededor de 273.186 personas afectadas (niños y adultos).

Las anteriores situaciones, sumadas al fenómeno de expansión urbana y densificación del suelo, no solo representan consecuencias al interior de las obras o para los trabajadores, sino en particular para las propiedades localizadas en sus proximidades, generando daños a las edificaciones y a la infraestructura de servicios públicos, comprometiendo su funcionalidad y afectando el desarrollo normal de las actividades públicas y privadas, lo que se traduce en los siguientes efectos (IDIGER, 2017, p.5):

- Daños en viviendas, pérdidas de enseres y muebles. 
- Daños en infraestructura de servicios públicos, transporte, espacio público y demás elementos expuestos.

- Pérdida de funcionalidad de los equipamientos públicos.

- Pérdidas económicas, obstrucción o cese de actividades económicas.

- Afectaciones a la población al interior y exterior de las edificaciones, heridos y, en ocasiones, pérdidas de vidas humanas.

\section{Riesgo por Incendios Forestales}

Este tipo de riesgo se refiere al fuego que se propaga sin control, sin límites preestablecidos, consumiendo material vegetal ubicado en áreas rurales de aptitud forestal o, en aquellas que, sin serlo, cumplan una función ambiental y cuyo tamaño es superior a 0.5 Ha. (IDIGER, 2017, p.15)

En Bogotá existen 122.258 hectáreas de suelo rural que pueden verse afectadas por un incendio forestal, de acuerdo con los análisis de ocurrencia de incendios forestales en Bogotá los años más críticos han sido: 2001, 2010, 2014 y 2016. (IDIGER, 2017, p.16).

Entre 2010 y 2016 se han atendido 4.860 incidentes forestales, distribuidos de la siguiente manera: 3.618 han sido quemas, 1.115 fueron conatos y el restantes 127 fueron incendios forestales, afectando un área total de $1.412 \mathrm{Ha}$, siendo el año 2016, donde se presentó la mayor afectación por incendios forestal en un área de 431 Ha. (IDIGER, 2017, p.17)

\section{Riesgo por inundación}

Las inundaciones son producidas por un exceso de agua, que invade cubriendo áreas urbanizadas o no, que en condiciones normales están secas. En Bogotá el agua fluye desde los cerros orientales por quebradas, ríos, humedales, hasta el río Bogotá, atravesando de oriente a occidente la ciudad. Para la ciudad, las mayores causas de inundación son las lluvias fuertes y de gran duración, generando volúmenes de agua que los ríos, humedales y quebradas no tienen la capacidad para recolectar y transportar (IDIGER, 2017, p.17).

Según el Plano Normativo De Amenaza de Inundación por Desbordamiento, registrado según la Resolución 858 de 2013 que actualiza el Plano Normativo del Decreto 190 del 2004: Se estima que 6.928,17 Ha de Bogotá corresponden a zonas o áreas donde existe una probabilidad de ocurrencia de inundaciones por desbordamiento de cauces naturales y/o cuerpos de agua intervenidos en diferentes niveles, con efectos potencialmente dañinos, en las zonas del río Tunjuelo, la quebrada Limas, la quebrada Chiguaza, el río Fucha, el río Juan Amarillo, los humedales Jaboque, Juan Amarillo, Conejera, Guaymaral, Torca y el río Bogotá. El área en amenaza alta es del orden de 1.904,1 Ha., en amenaza media de 3.920,70 Ha. y en baja, 1.097,37 Ha. (IDIGER, 2017, p17)

Así mismo, se establece que diez (10) de las veinte (20) localidades de la capital: Suba, Bosa, Engativá, Kennedy, Fontibón, Tunjuelito, Ciudad Bolívar, Rafael Uribe Uribe, Usaquén y Usme, tienen una afectación directa por la ocurrencia de inundaciones por desbordamiento en el Distrito Capital (IDIGER, 2017, p17). El fenómeno de La Niña, que se presentó durante los años 2010 - 2011, fue uno de los periodos más lluviosos, generando daños económicos, afectados y muertos (citado en IDIGER, 2017, p.17).

\section{Riesgo por Movimientos en Masa}

Un movimiento en masa es el proceso por el cual un volumen de material constituido por roca, suelo, escombros, o una combinación de cualquiera de estos, se desplaza por una ladera o talud (superficie inclinada) por acción de 
la gravedad. Entre ellos podemos mencionar: caídas y volcamientos, deslizamientos, flujos y reptaciones. En Bogotá los movimientos en masa se ven representados en afectaciones tales como:

- Daños físicos en viviendas y demás elementos expuestos.

- Pérdidas económicas.

- Afectaciones a la población.

- Heridos y pérdidas de vidas humanas.

- $\quad$ Pérdida de funcionalidad de equipamientos.

Más de 10.000 familias han sido incluidas en el programa de reasentamiento, siendo Ciudad Bolívar la localidad con mayor número de reasentamientos (más de 5.000), seguida de las localidades de Rafael Uribe Uribe (cerca de 2.000) y San Cristóbal (cerca de 1.500). En otras localidades como Usme, Usaquén, Santa Fe, Chapinero, Suba y Sumapaz, se han incluido familias a este programa (IDIGER, 2017, p.23).

Del total del área de suelo urbano del Distrito Capital, aproximadamente el $4 \%$ se encuentra categorizada en amenaza alta por movimientos en masa ( $2776 \mathrm{Ha}$ ), un $15 \%$ en amenaza media ( $16600 \mathrm{Ha}$ ) y un $12 \%$ en amenaza baja (11400 Ha) (IDIGER, 2017, p.23).

Las localidades con antecedentes por movimientos en masa son: Usaquén, Chapinero, San Cristóbal, Usme, Suba, Rafael Uribe y Ciudad Bolívar, correspondiente a más del 30 \% del área urbana. Se estima que más de 2’300.000 personas están ubicadas en zonas de amenaza por movimientos en masa. (IDIGER, 2017, p.23)

\section{Riesgo Sísmico}

El riesgo sísmico es la posibilidad de que ocurran en un lugar específico daños a las construcciones, afectaciones a la población y pérdidas económicas por un evento sísmico (terremoto). Para estimar el nivel de riesgo sísmico en un lugar hay varias metodologías que en general tienen en cuenta tres componentes básicos, que son: la amenaza, la vulnerabilidad y la capacidad de respuesta (IDIGER, 2017, p.4).

De acuerdo con los estudios adelantados por la Asociación Colombiana de Ingeniería Sísmica de Colombia, y por Ingeominas, en convenio con la Universidad Nacional, relacionados con las amenazas sísmicas de Colombia, la capital Bogotá se ubica en una zona intermedia de exposición frente a este tipo de riesgos (IDIGER, 2017, p.4). A continuación, se muestra la trazabilidad de los reportes que sobre este tipo de eventos se han presentado en Bogotá a lo largo de la historia (IDIGER, 2017, p.4).

\begin{tabular}{|c|c|c|c|c|}
\hline Año & Epicentro & Magnitud & $\begin{array}{l}\text { Intensidad } \\
\text { Bogotá }\end{array}$ & Afectaciones en Bogotá \\
\hline 1616 & Cajicá (Cund) & ? & $?$ & \\
\hline 1644 & Chipaque & $\sim 6$ & VI & Posible licuación de los márgenes del rí Tunjuelo \\
\hline 1646 & Sogamoso & $\sim 6$ & $?$ & \\
\hline 1724 & Chita (Boyacá) & $\sim 6^{2 / 4}$ & ? & \\
\hline 1743 & Páramo de Chingaza & $\sim 6^{1 / 2}$ & $?$ & $\begin{array}{l}\text { Afectó la ermita de Guadalupe, relatos de daños gravísimos } \\
\text { a iglesias y conventos. }\end{array}$ \\
\hline 1755 & Gámeza (Boy) & ? & ? & \\
\hline 1785 & $\begin{array}{l}\text { Suroriente } \\
\text { Cundinamarca }\end{array}$ & 6.8 & VII & $\begin{array}{l}\text { Afectó la ermita de Guadalupe, relatos de la severidad del } \\
\text { evento y de los daños. }\end{array}$ \\
\hline 1805 & Honda (Tolima) & 6,1 & IV & \\
\hline 1826 & Úmbita (Boy) & 6.5 & VII & \\
\hline 1827 & Timaná (Huila) & 7.1 & VIII & Afectó la ermita de Guadalupe \\
\hline 1875 & $\begin{array}{l}\text { Cúcuta (Nte de } \\
\text { Santander) }\end{array}$ & 6.8 & IV & \\
\hline 1884 & Herveo (Tolima) & 6.5 & IV & \\
\hline 1906 & Costa Pacífica & 6.8 & IV & \\
\hline
\end{tabular}




\begin{tabular}{|c|c|c|c|c|}
\hline 1911 & Yarumal (Antioquia) & 7.2 & IV & \\
\hline 1917 & Páramo Sumapaz & 6.9 & VIII & $\begin{array}{l}6 \text { muertos, } 12 \text { heridos, } 400 \text { casas afectadas y } 50 \text { colapsadas, } \\
\text { daños a la ermita de Guadalupe y de Chapinero }\end{array}$ \\
\hline 1923 & Medina (Cund) & $5 \cdot 9$ & VI & \\
\hline 1925 & Tuluá (Valle) & 6.8 & IV & \\
\hline 1935 & Pueblo Rico (Risaralda) & 6.2 & IV & \\
\hline 1938 & Eje cafetero & 7.0 & V & \\
\hline 1942 & Girardot (Cund) & 5.8 & V & \\
\hline 1957 & Málaga (Santander) & 6.6 & V & \\
\hline 1961 & Eje cafetero & 6.8 & V & \\
\hline 1962 & Maceo (Antioquia) & 5.6 & IV & \\
\hline 1962 & Eje cafetero & 6.8 & V & \\
\hline 1966 & Choachí (Cund) & 5.2 & VI & \\
\hline 1967 & Los Cauchos (Huila) & 7.0 & VII & $\begin{array}{l}13 \text { muertos, } 100 \text { heridos, } 30 \text { inmuebles afectados, daños a la } \\
\text { ermita de Guadalupe. }\end{array}$ \\
\hline 1967 & Betulia (Santander) & 6.8 & V & \\
\hline 1973 & Salento (Quindío) & 6.1 & IV & \\
\hline 1973 & $\begin{array}{l}\text { Convención (Nte de } \\
\text { Santander) }\end{array}$ & $5 \cdot 7$ & V & \\
\hline 1976 & Darién (Panamá) & $7 \cdot 3$ & IV & \\
\hline 1979 & El Cairo (Valle) & 7.2 & VI & \\
\hline 1988 & El Calvario (Meta) & 4.8 & IV & \\
\hline 1992 & Murindó (Antioquia) & 7.1 & V & \\
\hline 1993 & Puerto Rendón (Arauca) & 6.1 & IV & \\
\hline 1994 & Páez (Cauca) & 6.8 & V & \\
\hline 1995 & Tauramena (Casanare) & 6.5 & V & \\
\hline 1999 & Córdoba (Quindío) & 6.1 & III & \\
\hline 2008 & Quetame (Cund) & $5 \cdot 7$ & 1 & Causó daños menores en algunos edificios \\
\hline 2013 & Guaitarilla (Nariño) & 7 & IV & \\
\hline
\end{tabular}

Tabla 2. Sismos históricos sentidos en Bogotá. Nota: Recuperado de: Instituto Distrital de Gestión de Riesgos y Cambio Climático. IDIGER (19 de Octubre de 2017) http://www.idiger.gov.co/rsismico .

\section{Riesgo Tecnológico}

El riesgo tecnológico, por lo general, representa pérdidas potenciales por daños, interrupción, alteración o fallas en el funcionamiento u operación, derivadas del uso o dependencia de equipos, sistemas de distribución, productos, sustancias químicas o biológicos, y demás componentes de la tecnología, originados en sucesos antrópicos, naturales, socio-naturales y propios de la operación. (IDIGER, 2017, p.23)

Según el informe de la Secretaría Distrital de Salud - Subsecretaría de Salud Pública Boletín Seguridad Química (2014). A continuación, se muestra Distribución de almacenamiento de sustancias peligrosas por localidad en todas las actividades económicas (IDIGER, 2017, p.23).

La información presentada corresponde a una muestra de una recopilación de información sobre los temas de gestión de Riesgos que adelanta la Alcaldía Mayor de Bogotá, mediante el Instituto Distrital de Gestión de Riesgos y Cambio Climático (IDIGER), que va de la mano de los Planes Escolares de Gestión de Riesgos y cambio climático (PEGR), que se describe como sigue: "Por lo cual se adoptan los lineamientos para la elaboración, registro y verificación de los Planes Escolares de Gestión de Riesgos y Cambio Climático (PEGR-CC) en las instituciones y establecimientos oficiales y privados, de atención integral a la primera infancia, infancia y adolescencia, instancias educativas y educación para el trabajo y Desarrollo Humano del Distrito Capital" (Resolución 592 de 2015). 


\begin{tabular}{|lcc|}
\hline \multicolumn{1}{c}{ Localidad } & Cantidad Total Peligrosos (kg) & $\%$ de Aporte a la Cantidad Total \\
\hline Antonio Hariño & 1271085,629 & 3,102 \\
\hline Barrios Unidos & 762862,8912 & 1,861 \\
\hline Bosa & 1635221,348 & 3,990 \\
\hline Candelaria & 4126,193214 & 0,010 \\
\hline Chapinero & 530399,4444 & 1,294 \\
\hline Ciudad B olívar & 2368508,443 & 5,779 \\
\hline Engativá & 2241931,994 & 5,470 \\
\hline Fontibón & 10330535,1 & 25,207 \\
\hline Kennedy & 3968608,858 & 9,684 \\
\hline Mártires & 952198,8677 & 2,323 \\
\hline Puente Aranda & 5583321,86 & 13,624 \\
\hline Rafael Uribe & 1028446,238 & 2,509 \\
\hline San Cristóbal & 645617,1833 & 1,575 \\
\hline Santafé & 742292,4841 & 1,811 \\
\hline Suba & 2737926,837 & 6,681 \\
\hline Sumapaz & 4068,521554 & 0,010 \\
\hline Teusaquillo & 544389,3518 & 1,328 \\
\hline Tunjuelito & 2096528,079 & 5,116 \\
\hline Usaquén & 2973195,197 & 7,255 \\
\hline Usme & 561491,4457 & 1,370 \\
\hline
\end{tabular}

Tabla 3. Distribución de almacenamiento de sustancias peligrosas. 2017. Nota: Recuperado de: Instituto Distrital de Gestión de Riesgos y Cambio Climático. IDIGER (19 de octubre de 2017) http://www.idiger.gov.co/rtecnologico.

De manera que ya existen estrategias sobre el particular, como lo registra el denominado SURE-Sistema Único de Registro Escolar, en el que se formulan herramientas pedagógicas y conceptuales para trabajar con la comunidad educativa en el proceso de toma de conciencia sobre los riesgos a que se encuentran expuestos y la mejor manera de superarlos.

Sin embargo, la gestión del riesgo parte del reconocimiento de que los desastres constituyen problemas generados en los procesos de desarrollo y, por tanto, es necesario fortalecer las capacidades y la articulación entre las diversas instituciones, organizaciones y los actores del desarrollo para reducir los riesgos.

Desde un enfoque de derechos, la gestión de riesgos supone condiciones más favorables para que los habitantes de un territorio ejerzan el derecho a la vida, que es indesligable de los derechos a la alimentación, salud, educación, vivienda y a disfrutar de un ambiente integralmente sano. En un territorio capaz de garantizarles a sus habitantes la realización de sus derechos.

De ahí la importancia de la gestión de riesgos en la institución educativa pues implica la reducción de la vulnerabilidad frente a las amenazas, la contribución del proceso educativo en la generación de una cultura de prevención, para la institución y la comunidad y el fortalecimiento de la resiliencia de la comunidad educativa, para responder a situaciones de emergencia.

A esto se suma el planteamiento registrado en el informe del Banco Interamericano de Desarrollo División de Medio Ambiente, Desarrollo Rural y Gestión del Riesgo de Desastres (INE/RND) sobre indicadores de Riesgo de desastres y gestión de riesgos, en su nota técnica IDB -TN-792 del año 2010, así contemplado:

Los desastres son eventos socioambientales cuya materialización es el resultado de la construcción social del riesgo. Por lo tanto, su reducción debe hacer parte de los procesos de toma de decisiones, no sólo en el caso de reconstrucción pos-desastre, sino también en la formulación de políticas públicas y la 
planificación del desarrollo. Por esta razón, es necesario fortalecer el desarrollo institucional y estimular la inversión para la reducción de la vulnerabilidad con fines de contribuir al desarrollo sostenible de los países. (BID, 2010, P.1).

Para ilustrar un poco la cifra de la población nacional hasta el año 2010, el país contaba con 45'508.205 habitantes, reportando el mayor número en su capital Bogotá que registró 7’363,782 habitantes, ciudad sobre la cual se realizó el marco de la investigación. (DANE, 2010, p.15)

\begin{tabular}{|l|r|r|r|r|r|r|r|}
\hline \multicolumn{1}{c|}{ Población } & \multicolumn{1}{|c|}{1951} & \multicolumn{1}{c|}{1973} & \multicolumn{1}{c|}{1985} & \multicolumn{1}{c|}{1993} & \multicolumn{1}{c|}{2005} & 2010 \\
\hline Total nacional & $11^{\prime} 548.172$ & $22^{\prime} 915.229$ & $30^{\prime} 062.198$ & $37^{\prime} 664.711$ & $42^{\prime} 890.642$ & $45^{\prime} 508.205$ \\
\hline Población urbana & $4^{\prime} 468.437$ & $13^{\prime} 548.183$ & $19^{\prime} 628.428$ & $25^{\prime} 849.387$ & $31^{\prime} 889.299$ & $34^{\prime} 388.013$ \\
\hline \% Población urbana & $38,69 \%$ & $59,12 \%$ & $65,29 \%$ & $68,63 \%$ & $74,40 \%$ & $75,60 \%$ \\
\hline \# Municipios > 1 millón de habitantes & 0 & 2 & 3 & 4 & 4 & 4 \\
\hline Población municipios > 1 millón de habitantes & 0 & $4^{\prime} 025.781$ & $7^{\prime} 145.898$ & $10^{\prime} 080.022$ & $12^{\prime} 320.927$ & $13^{\prime} 138.110$ \\
\hline \multicolumn{1}{|c|}{ Bogotá } & 715.250 & $2^{\prime} 861.913$ & $4^{\prime} 236.490$ & $5^{\prime} 413.484$ & $6^{\prime} 840.166$ & $7^{\prime} 363.782$ \\
\hline
\end{tabular}

Tabla 4. Cifras de la población nacional hasta el año 2010. Información que arrojó la tabla del Dane, 2010 Análisis de la gestión del riesgo de desastres en Colombia: un aporte para la construcción de políticas públicas Pg. 15.

Vale la pena destacar el esfuerzo de la Alcaldía mayor de Bogotá para la reducción y manejo integral del riesgo de familias localizadas en zonas de alto riesgo. No se quieren tener más cifras como las que presentaba en su momento el DNP (Departamento Nacional de Planeación), de 3.181 muertos y 12.3 millones de afectados en desastres naturales ocurridos entre los años 2006 y 2014 (UNGRD, 2014, p.1), según la base de datos del reporte de Emergencias de la Unidad Nacional para la Gestión del Riesgos de Desastres (UNGRD).

Una primera conclusión para el Departamento Nacional de Planeación (DNP) es que la población colombiana que sufrió algún tipo de afectación en el período 2006-2014, por desastres de origen natural, equivale al $26 \%$ de la población nacional proyectada por el DANE para 2015. Del cálculo de 48.203.405 habitantes, la cuarta parte ha resultado damnificada: 12.298.849. De esta cifra, sólo por inundaciones, el total de personas afectadas es del $19 \%$ de la población calculada total: 9.390.554 de personas. (DANE, 2015, p.1)

Para Simón Gaviria Muñoz, director del Departamento Nacional de Planeación (DNP) para entonces, desde el ordenamiento territorial se pueden prevenir los desastres, si se saben identificar las amenazas y se utiliza de manera adecuada el territorio (DNP, 25/05/2015).

Con la siguiente gráfica, se representan la proporción de frecuencia por tipo de eventos presentados en Bogotá y en Colombia. Las cifras sugieren que hay mucho por hacer, por esto es necesaria la vinculación de los estudiantes a los programas ya diseñados. Se recuerda que la educación es una inversión, y las capacidades se desarrollan a edades tempranas (Patrinos, 2016). 

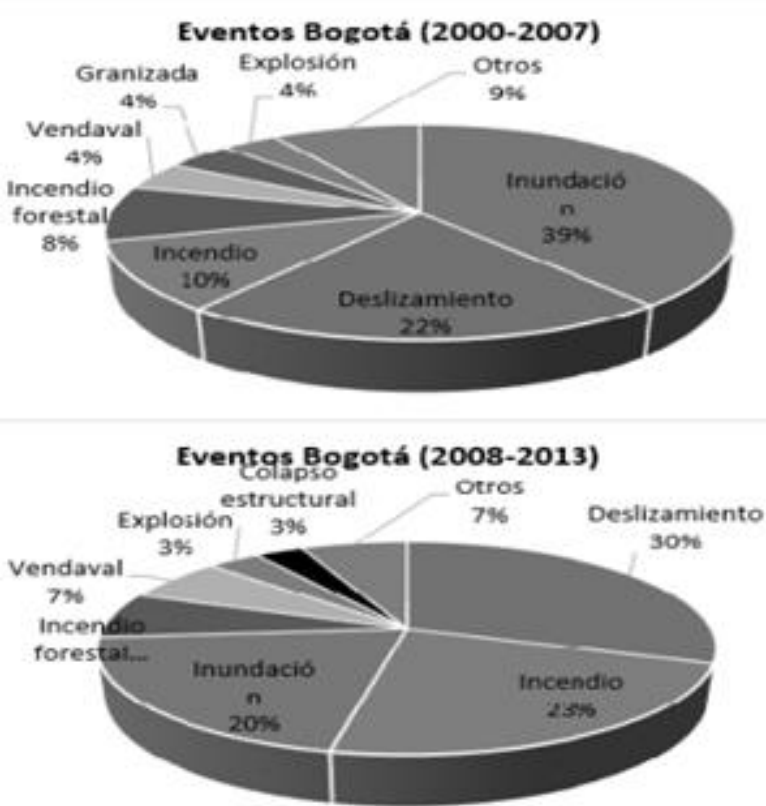
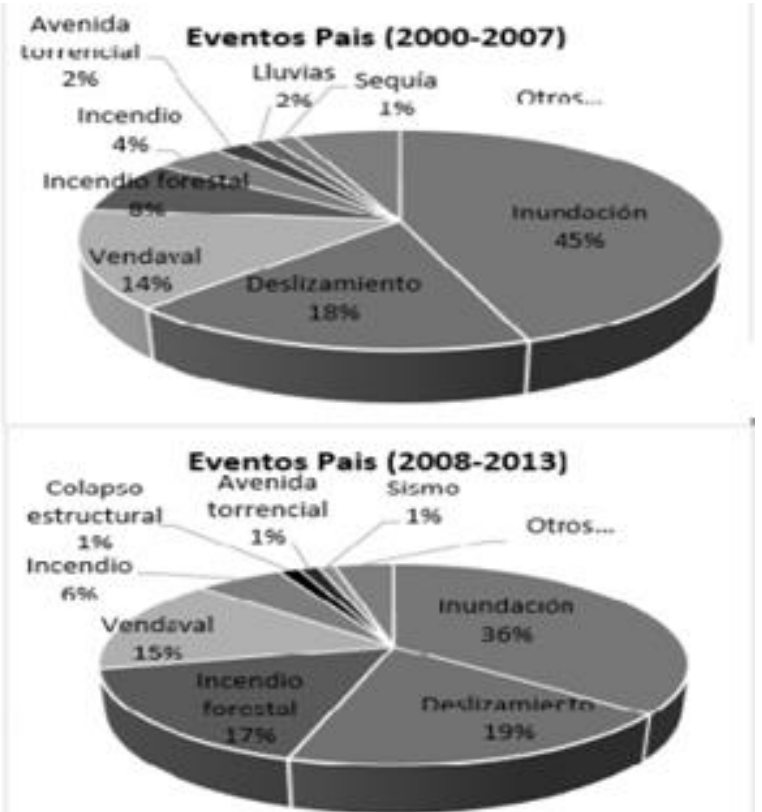

Gráfico 2.. frecuencia por tipo de eventos presentados en Bogotá y en Colombia. Nota: Recuperado de: Instituto Distrital de Gestión de Riesgos y Cambio Climático. IDIGER (19 de octubre de 2017) http://www.idiger.gov.co/rcc\#_idiger.

La necesidad expuesta previamente se corrobora con declaraciones como las de Francis Ghesquiere, director del grupo de prácticas de Gestión de Riesgos de Desastres del Banco Mundial, en las que afirma que Bogotá, al ser una ciudad en proceso de crecimiento, es el ejemplo perfecto para entender la importancia de integrar el plan de desarrollo con la política de gestión y atención de emergencias. "La capital es una de las primeras ciudades en el mundo que realmente utilizó un modelo para guiar intervenciones de reducción de vulnerabilidad. Eso es una demostración de la coherencia y el proceso proactivo que tuvo la ciudad (Palomino, Jhon. 22 de octubre de 2013).

De ahí que sea evidente la necesidad de apoyar los planes escolares en los que se discute el bienestar de una población que merece mejor calidad de vida. En consecuencia, se considera importante llevar estos conocimientos a las aulas escolares de los colegios, distritales y privados, para enfocar desde temprana edad la concientización sobre los temas de riesgos e incorporar la gestión del riesgo en todas las actividades cotidianas.

\section{La razón de ser de los seguros desde la formación en riesgos}

Para lograr entender la situación actual que vive Colombia sobre cultura del seguro, y su forma de entender éste como un gasto y no como una inversión, es necesario realizar un pequeño ejercicio deductivo. Según Valora Analitik, Colombia participa con un 5.3\% del mercado asegurador latinoamericano, lo que equivale al $2,9 \%$ de PIB en 2017. Los países que lideraron este listado fueron Brasil (49,6\%) y México (15,1\%).

La cifra anterior permite suponer que, desafortunadamente en Colombia, los seguros no cobran la importancia necesaria en la economía. A continuación, se presenta el resultado del Primer Estudio de Demanda de Inclusión Financiera en Seguros, realizado por Banca de las Oportunidades, la Superintendencia Financiera de Colombia (SFC) y Fasecolda, que contempló 6.520 hogares colombianos situados en Antioquia, Atlántico, Regiones Central, Oriental y Pacífica, en el Valle del Cauca y Bogotá: 


\begin{tabular}{|c|c|c|c|}
\hline & $\begin{array}{l}\text { Razones para no tener un } \\
\text { seguro }\end{array}$ & $\begin{array}{l}\text { Total } \\
\text { nacional }\end{array}$ & Bogotá \\
\hline & $\begin{array}{l}\text { Los seguros son muy } \\
\text { costosos }\end{array}$ & $40,90 \%$ & $33,20 \%$ \\
\hline & $\begin{array}{l}\text { No confían en las } \\
\text { aseguradoras }\end{array}$ & $14,00 \%$ & $16,50 \%$ \\
\hline & $\begin{array}{l}\text { No tienen nada para } \\
\text { asegurar }\end{array}$ & $11,30 \%$ & $12,70 \%$ \\
\hline & $\begin{array}{l}\text { Se requieren muchos } \\
\text { trámites o requisitos para } \\
\text { adquirir un seguro }\end{array}$ & $5,60 \%$ & $4,60 \%$ \\
\hline & $\begin{array}{l}\text { No saben qué es un } \\
\text { seguro, ni para qué sirve }\end{array}$ & $5,40 \%$ & $4,00 \%$ \\
\hline & Otra razón & $22,80 \%$ & $29,00 \%$ \\
\hline
\end{tabular}

La tabla 5 muestra que la razón más importante por la que los colombianos no adquieren seguros es el precio para obtenerlo, por la falta de seguros a la medida de los riesgos de los asegurados que vuelvan el precio algo más asequible. Al respecto Ruiz (2017, p. 15) señalaba que: "Los mercados de seguros de América Latina siguen en un subdesarrollo relativo, están creciendo pero sujeto a una cultura de países desarrollados que valoran desde el punto de vista de función social como en finanzas sus productos y servicios.". Todos los países deberían ver los seguros como una función social, como una forma de cuidar el patrimonio de cada ciudadano y, a la vez, de toda la nación.

Hoy en día las pólizas de seguros se perciben como costosas por el desconocimiento sobre el beneficio que ofrecen; además, se consideran un gasto, al no hacerse tangible el beneficio esperado. Respuestas como no tener nada que asegurar y no saber qué es un seguro, que equivalen a un $16,7 \%$ de la población encuestada en Bogotá, demuestra la necesidad de una formación desde temprana edad sobre riesgos, para que se logre entender el importante papel que juegan los seguros desde las finanzas personales, más allá de ser un producto del mercado.

Para que los seguros dejen de ser vistos como un gasto y más bien se tomen como una inversión, lo primero que se deberá hacer será educar sobre la exposición a diferentes riesgos a los que diariamente están expuestos los jóvenes en una ciudad como Bogotá, y a concientizarlos sobre la importancia y el impacto que estos generan.

Cuando se dice que el seguro debe ser visto como una inversión, no es otra cosa que pensar que al asegurar la vida y los bienes ante una catástrofe natural, o eventualidad que materialice el riesgo, se está garantizando de una forma responsable, la mitigación de las pérdidas y daños morales y físicos ocasionados por dicha eventualidad. Al formar desde temprana edad a los adolescentes bajo la premisa anterior, podríamos estar garantizando un mercado asegurador próspero y evolutivo.

Los riesgos desde una perspectiva juvenil

Igualmente, es importante entender lo que los jóvenes opinan, piensan y saben sobre este tema de los riesgos, y su interés por involucrarse en ello. Por lo anterior, a continuación, se presentan las respuestas a una encuesta realizada a 97 estudiantes de grados $10^{\circ}$ y $11^{\circ}$ de dos colegios, uno Privado y el otro de carácter Público. En la primera columna del gráfico 3 se encuentran las respuestas de 59 estudiantes del colegio privado, en la segunda columna están las respuestas de los 38 estudiantes del colegio público y, en la tercera columna, está la compilación de las respuestas de los dos colegios: 


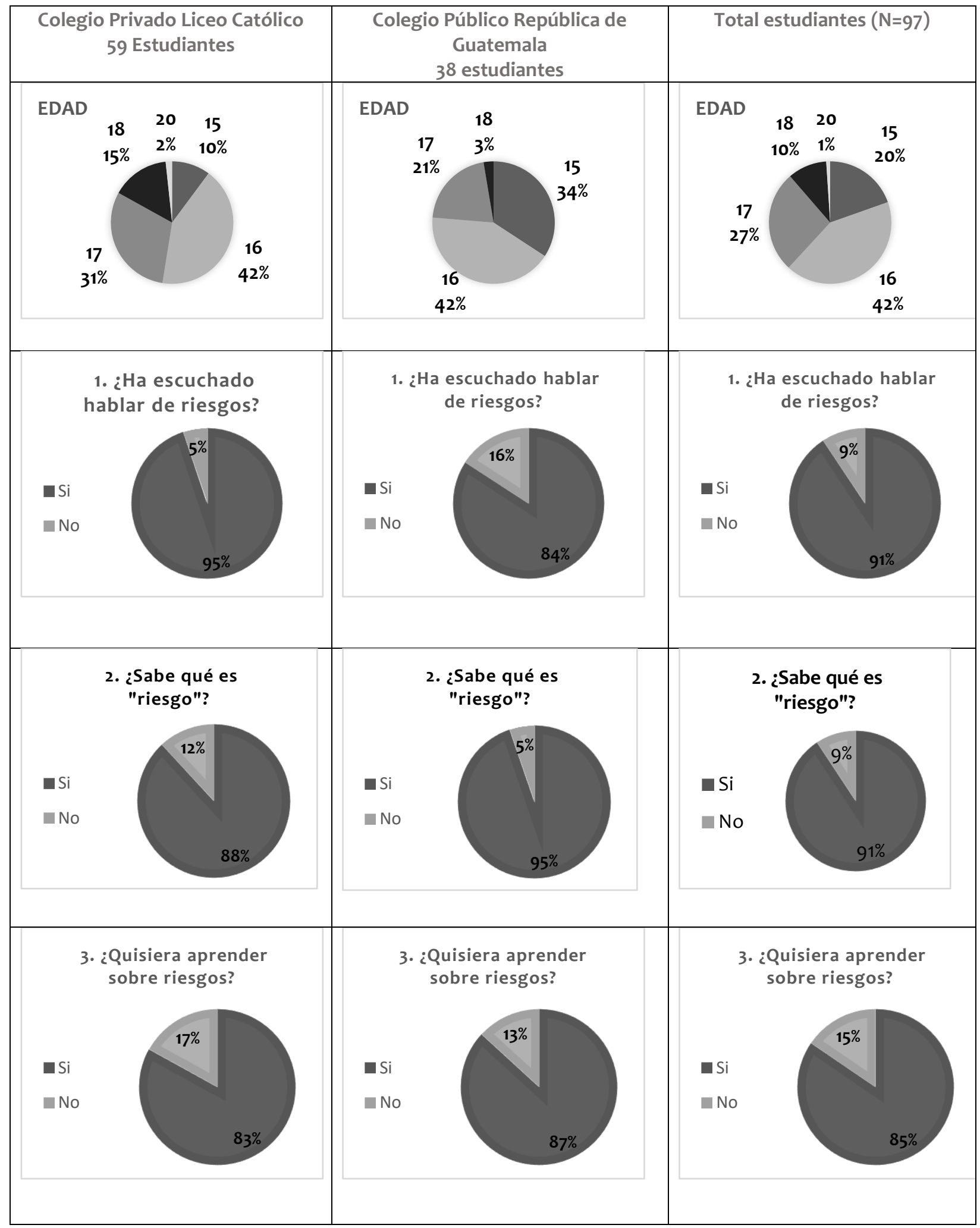




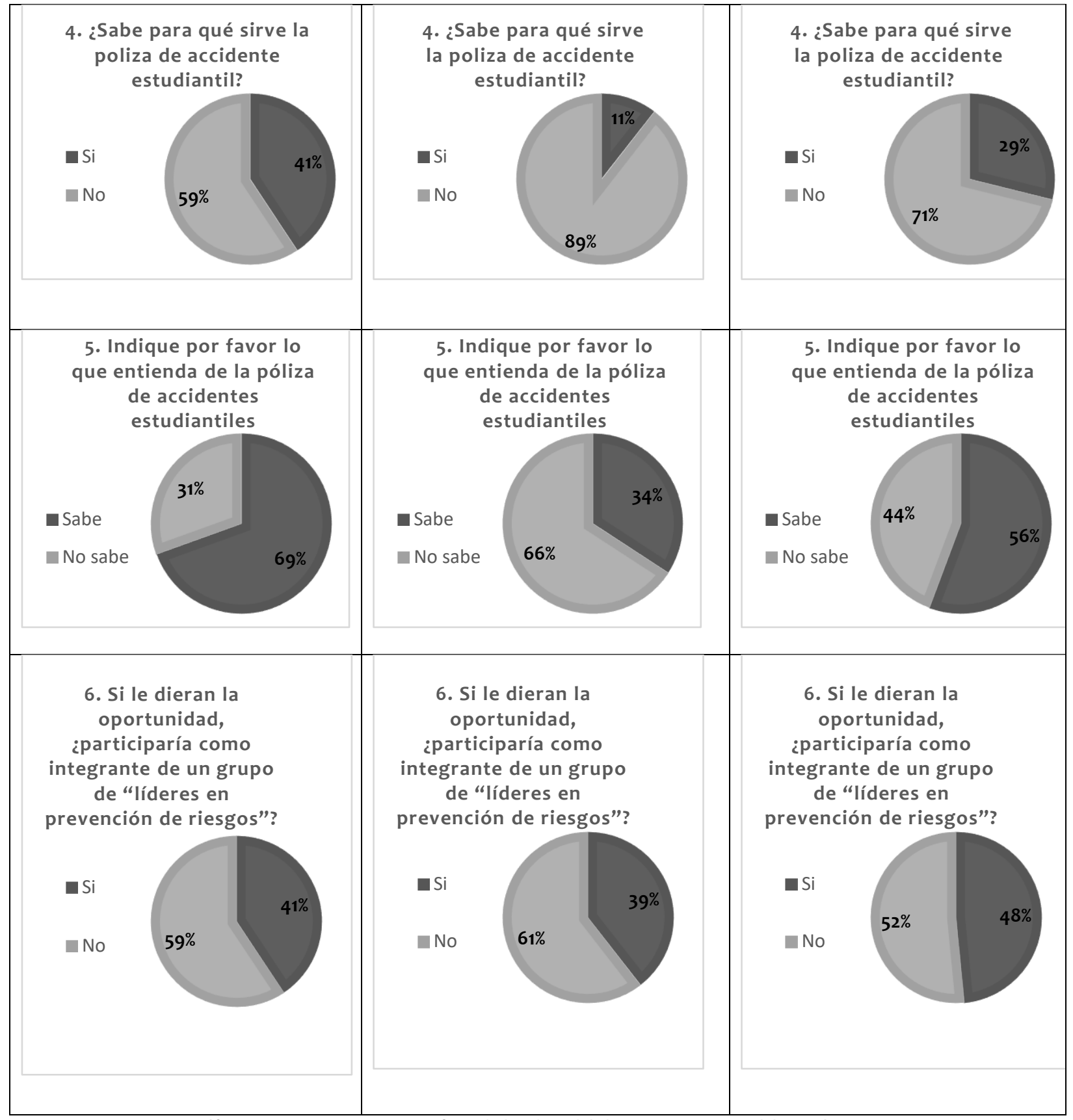

Gráfico 3. Respuestas a preguntas formuladas al total de la muestra. Fuente: Elaboración propia.

Demográficamente, la encuesta fue resuelta por estudiantes de entre los 16 y 17 años, en su mayoría. Para las preguntas 1, 2 y 3, la mayoría ha escuchado, sabe y quiere aprender sobre riesgos. Más allá de si saben o no, se resalta su interés por querer aprender, lo que permite pensar en la gran oportunidad que se tiene para desarrollar un programa didáctico de riesgos para jóvenes adolescentes.

Siendo la póliza estudiantil común para ambos colegios, que busca brindar protección ante diversos eventos, especialmente accidentes dentro y fuera de las instituciones educativas, las preguntas 4 y 5 buscaban identificar si los estudiantes podían relacionar el conocimiento que creían tener sobre riesgos con una póliza de uso cercano 
a su rol como estudiantes. En esta pregunta hubo diferencias evidentes en los dos escenarios; un alto porcentaje de estudiantes del colegio público no sabía para que servía la póliza, mientras que para el colegio privado la situación fue más balanceada, con una diferencia de 9 puntos porcentuales entre los que sabían y los que no; a pesar de lo anterior, un mayor número de estudiantes sabía cómo funcionaba. Esto permite concluir que el conocimiento sobre los riesgos asociados a la póliza les permite a los estudiantes deducir cómo funciona.

Finalmente, para la pregunta 6, un poco más de la mitad de los estudiantes no están interesados en participar en un grupo de líderes de prevención de riesgos; esto puede estar relacionado con el poco conocimiento e información que tienen referente al tema; de las respuestas a la pregunta 3 se observa que la mayoría de los estudiantes quisiera aprender sobre riesgos, al recibir esta formación seguramente se tendrán más estudiantes interesados en temas relacionados con la prevención de riesgos.

De la pregunta 7, cuyos resultados se presentan a continuación, se puede deducir que los jóvenes pueden identificar riesgos tales como robo, accidentes de tránsito o desastres naturales, luego de indicar que sabían a qué riesgos estaban expuestos diariamente; quiere decir entonces que para estos dos grados $\left(10^{\circ}\right.$ y $\left.11^{\circ}\right)$ ya existe alguna claridad sobre las situaciones que se pueden presentar cuando se habla de riesgos, lo cual permite tener como referencia un punto de partida y concluir que, iniciar el proceso de formación en esos dos grados puede ser una opción acertada. En esta pregunta resulta interesante observar lo que escribieron los estudiantes sobre los riesgos a los cuales diariamente están expuestos en los dos escenarios, más allá de mirar si lo que escribieron era correcto o no. Por ejemplo, para el colegio privado, los tres riesgos que más escribieron fueron accidentes de tránsito, robo y desastres naturales, para el colegio público fueron robo, accidentes personales y drogas. Lo anterior muestra que, en los dos escenarios, hay diferencias sobre lo que ellos consideran que puede ser un riesgo en sus vidas.

\section{Colegio Privado}

\section{7. ¿CONOCE LOS RIESGOS \\ A LOS CUALES ESTÁ \\ EXPUESTO DIARIAMENTE?}

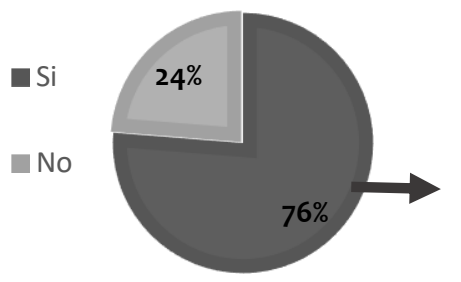

Si su respuesta fue sí, por favor indique al menos dos:

\begin{tabular}{|c|r|}
\hline Accidente de transito & $24,3 \%$ \\
\hline Robo & $22,4 \%$ \\
\hline Desastres naturales & $13,8 \%$ \\
\hline Escolar & $6,6 \%$ \\
\hline Salud & $5,3 \%$ \\
\hline Accidente personal & $5,3 \%$ \\
\hline No sabe no responde & $5,3 \%$ \\
\hline Incendio & $3,3 \%$ \\
\hline Muerte & $2,6 \%$ \\
\hline Laboral & $2,6 \%$ \\
\hline Secuestro & $2,0 \%$ \\
\hline Económico & $1,3 \%$ \\
\hline Contaminación & $0,7 \%$ \\
\hline Terrorismo & $0,7 \%$ \\
\hline Accidentes domésticos & $0,7 \%$ \\
\hline Daños por obras & $0,7 \%$ \\
\hline Riesgo de no tener seguro & $0,7 \%$ \\
\hline Académico & $0,7 \%$ \\
\hline Daños hogar & $0,7 \%$ \\
\hline Perder el año & $0,7 \%$ \\
\hline & \\
\hline
\end{tabular}


Colegio Público

7. ¿CONOCE LOS RIESGOS

A LOS CUALES ESTÁ

EXPUESTO DIARIAMENTE?

$\square \mathrm{Si}$

No

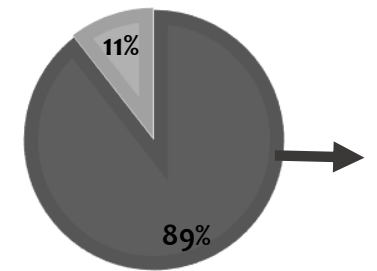

Si su respuesta fue sí, por favor indique al menos dos:

\section{Total estudiantes}

7. ¿Conoce los riesgos a

los cuales está expuesto diariamente?

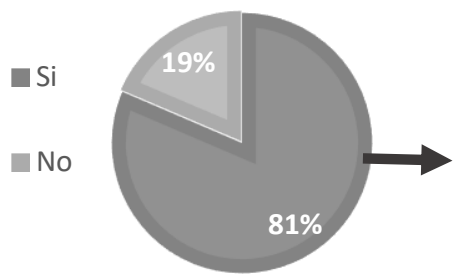

Si su respuesta fue sí, por favor indique al menos dos:

\begin{tabular}{|c|c|}
\hline Robo & $22,5 \%$ \\
\hline Accidente personal & $16,7 \%$ \\
\hline Drogas & $14,2 \%$ \\
\hline Accidente de transito & $10,0 \%$ \\
\hline Secuestro & $9,2 \%$ \\
\hline Desastres naturales & $8,3 \%$ \\
\hline Muerte & $3,3 \%$ \\
\hline Salud & $3,3 \%$ \\
\hline Terrorismo & $1,7 \%$ \\
\hline Riñas & $1,7 \%$ \\
\hline Prostitución & $1,7 \%$ \\
\hline Perder el año & $1,7 \%$ \\
\hline No sabe no responde & $1,7 \%$ \\
\hline Incendio & $0,8 \%$ \\
\hline Económico & $0,8 \%$ \\
\hline Daños hogar & $0,8 \%$ \\
\hline Denorte & $0.8 \%$ \\
\hline Robo & $22,4 \%$ \\
\hline Accidente de transito & $18,0 \%$ \\
\hline Desastres naturales & $11,4 \%$ \\
\hline Accidente personal & $10,3 \%$ \\
\hline Drogas & $6,3 \%$ \\
\hline Secuestro & $5,1 \%$ \\
\hline Salud & $4,4 \%$ \\
\hline Escolar & $3,7 \%$ \\
\hline No sabe no responde & $3,7 \%$ \\
\hline Muerte & $2,9 \%$ \\
\hline Incendio & $2,2 \%$ \\
\hline Laboral & $1,5 \%$ \\
\hline Terrorismo & $1,1 \%$ \\
\hline Económico & $1,1 \%$ \\
\hline Perder el año & $1,1 \%$ \\
\hline Riñas & $0,7 \%$ \\
\hline Daños hogar & $0,7 \%$ \\
\hline Prostitución & $0,7 \%$ \\
\hline Contaminación & $0,4 \%$ \\
\hline Accidentes domésticos & $0,4 \%$ \\
\hline Daños por obras & $0,4 \%$ \\
\hline Riesgo de no tener seguro & $0,4 \%$ \\
\hline Deporte & $0,4 \%$ \\
\hline Insultos & $0,4 \%$ \\
\hline
\end{tabular}

Gráfico 4. Respuestas al tipo de riesgos identificados por naturaleza de la Institución Educativa. Fuente: Elaboración propia.

Se tomó la decisión de realizar esta encuesta a los grados $10^{\circ}$ y $11^{\circ}$, para obtener una perspectiva juvenil de dos colegios, uno de carácter privado y otro público, con la finalidad de identificar los riesgos asociados a ambos escenarios de situaciones socioeconómicas diferentes: 
La información recopilada se complementó con una entrevista que muestra el punto de vista gerencial enmarcado en un enfoque académico, destacando los aportes del entrevistado en materia de riesgos. Al respecto cabe destacar que no basta tener en cuenta los conceptos asociados al riesgo a nivel organizacional, sino que también debe tomarse en consideración otros recursos, en este caso los jóvenes, hacia quienes estamos inclinando la propuesta para adoptar los programas de formación de riesgos desde las aulas.

Las preguntas formuladas y sus respectivas respuestas fueron las siguientes:

1. Desde su experiencia, ¿Cuál es el concepto que cree tiene la sociedad Bogotana sobre temas de Riegos y Seguros?

Considero que es un concepto bastante sesgado, en cuanto a que está relacionado básicamente a eventos negativos que le pueden ocurrir y también bastante sesgado a los impactos que pueden llegar a tener los eventos naturales sobre sus vidas o sus condiciones normales. Digo que sesgado porque el riesgo al final del día es una incertidumbre, que una cosa buena o mala le pase a uno en cualquier situación de su vida cotidiana. Entonces vemos lo primero, que no es únicamente un concepto negativo, sino que es un concepto negativo o positivo. $Y$ lo segundo, que no es únicamente un tema relacionado con temas de la naturaleza sino que uno puede tener riesgos financieros, riesgos personales, riesgos reputacionales, a nivel de compañía, riesgos operacionales, entonces considero que hace falta bastante en este tema de educación frente a los riesgos y al entendimiento de lo que es realmente un riesgo.

2. ¿Considera que Chile tiene Cultura de Seguros? ¿Cómo es esa cultura?, ¿Cómo cree que Bogotá podría llegar a ese nivel cultural?

Yo creo que el caso de Chile, al igual que al de México, hablando de países latinoamericanos, son excepcionales por la situación catastrófica que se les ha presentado. Ellos ya han vivido lo que es una catástrofe y saben las consecuencias que conlleva el no tener asegurado el patrimonio, hablando puntualmente de temas patrimoniales, lo que ha hecho que la penetración del seguro sea mucho más alta allá que en otros países, como el caso de Colombia. Uno también podría tener un ejemplo claro un poco distinto como el de Estados Unidos, donde realmente hay una cultura de Seguro, no por el hecho mismo de que estén enfrentados a ciertas situaciones de la naturaleza que los conllevan a que periódicamente siempre tengan unos eventos catastróficos, sino que para ellos conceptualmente, en su educación, siempre han tenido la idea de proteger tanto su patrimonio como su vida y su salud. Es un tema cultural. Al final del día para ellos es parte de su cultura y de sus gastos. Acá uno lo ve más como un lujo el que tiene un seguro para su apartamento, el que puede pagar una póliza de salud, es porque tiene unos excedentes de liquidez que le permiten hacer eso y no porque uno de pronto diga no me alcanza por este lado, pero si recorto estos gastos entonces si llego y aseguro esto. Entonces no es un tema tan de cultura sino es un poco diferente.

3. ¿Cree usted que, por medio de la educación en temas de Riesgos, desde temprana edad, se pueda aportar a la concientización de las personas para mitigar su exposición al riesgo?

Absolutamente. Creo que es un tema que se puede trabajar con educación. Es un tema que debería formar parte de esa educación integral de los niños para que se concienticen y sepan lo que hemos dicho... no necesariamente estamos hablando de situaciones adversas sino también de situaciones positivas y es cómo uno enfrentarse a esas incertidumbres, cómo afrontarlas y qué hacer para mitigar o aprovechar los impactos que esas situaciones le puedan generar o materializar a ellos en su vida.

4. ¿Cuál cree que sería el impacto, o lo que lograría, la implementación de formación desde el colegio en temas de riesgos? 
Creo que eso generaría una mayor concientización de lo expuesto que estamos a ciertas situaciones y por decirlo de alguna manera los controles que deberíamos entrar a implementar para mitigar el impacto de esas situaciones, entonces yo creo que, así como a uno le enseñan matemáticas, español, geografía, debería uno entrar a entender este tipo de situaciones. Porque al final del día es parte de la teoría causa-efecto. Todo lo que yo haga va a tener un efecto a qué me estoy enfrentando, a qué me estoy exponiendo, cómo estoy previendo esas situaciones, cómo preveo el futuro, cómo hago para mitigar esos impactos.

Todo es ganancia, en la implementación de la formación desde el colegio en temas de riesgos, no hay situación adversa que uno pueda prever, no la hay.

5. ¿Cuáles cree que son las cinco cosas que mínimo debe tener un programa ideal para formar a jóvenes (15 -17 años) en temas de riesgos?

- Primero una definición de lo que es riesgo.

- Segundo los tipos de riesgos, que también hay diferentes tipos de clasificaciones. Se tendría que entrar a generar algún tipo de programa donde la clasificación sea llamativa para los niños y así puedan entrar a entender de qué estamos hablando.

- Mitigar o Maximizar el impacto de esos riesgos positivos o negativos, que esto va muy a asociado a cómo prepararlos para afrontar ese tipo de situaciones.

- Situaciones o experiencias vivenciales, o sea, cómo personas que les pudieran ir a hablar de experiencias o situaciones que se les haya presentado, cómo lo han afrontado, si tenían seguro o no tenían seguros para que eso también los toque un poco más y por un lado sepan que no es un tema por allá traído de los cabellos sino que es algo de lo que realmente estamos enfrentados, que sepan que es algo que van a tener que estar preparados y que van a tener que enfrentar.

6. Una vez contextualizado sobre la presente investigación, se formuló la siguiente pregunta ¿Qué opinión tiene sobre nuestra investigación? ¿Qué recomendación haría para lograr el éxito en este proyecto?

Es una muy buena propuesta, creo que si lo que tienen conceptualmente estructurado se llega a materializar sería estupendo. Porque como se los mencionaba al principio, el tema de riesgos es un tema cultural, es un tema de concientización en el cual no trabajamos y si lo trabajamos desde los niños creo que vamos a tener unas generaciones futuras con una mayor preparación más consiente frente a los riesgos a los que estamos expuestos, y hacerlo como consejo, hacerlo supremamente simple porque uno normalmente cuando habla de estos temas de riesgos, y por ejemplo cuando se habla de riesgos financieros y elementos que conceptualmente son bastante densos, puede que se pierda la atención de lo que realmente se quiere hacer, y es que se lleve y transmita el mensaje de concientización a los niños, entonces debería hace ser algo realmente simple que les llegue, que les toque para que eso les quede a futuro.

Importancia de la participación de los jóvenes en la prevención de riesgos

Después de elaborar esta investigación, y contemplando los diferentes escenarios, entendiendo la situación a nivel de riesgos de una ciudad como Bogotá, la opinión de algunos expertos y el punto de vista de los adolescentes (basado en el resultado de las encuestas realizadas en las aulas escolares en el que se identifica un desconocimiento parcial en temas de riesgos), consideramos de vital importancia involucrar a los entes académicos para poner en práctica los programas de prevención de riesgos, motivando a los estudiantes a ser actores principales, comprometidos consigo mismo, con su entorno familiar y social, a partir de sus propias vivencias. 
Bajo esta perspectiva, y a partir de la experiencia académica en la Especialización en Gerencia de Riesgos y Seguros del Politécnico Grancolombiano, se abre una oportunidad de compartir con la población adolescente la temática de un programa académico sobre Riesgos, que brinde innumerables beneficios para la sociedad bogotana, pensando en estudiantes de los grados $10^{\circ}$ y $11^{\circ}$. De antemano debemos dejar claro dos aspectos; el primero, esta iniciativa se presenta con base en nuestra experiencia en el gremio asegurador y como estudiantes y docente de la Especialización de Gerencia de Riesgos y Seguros, entendiendo así que existen temas netamente pedagógicos y académicos los cuales deben ser revisados e incorporados para una adecuada implementación; segundo, todas las temáticas que se plantean a continuación deben estar acompañadas de un material didáctico y pedagógico que atraiga la atención de los estudiantes:

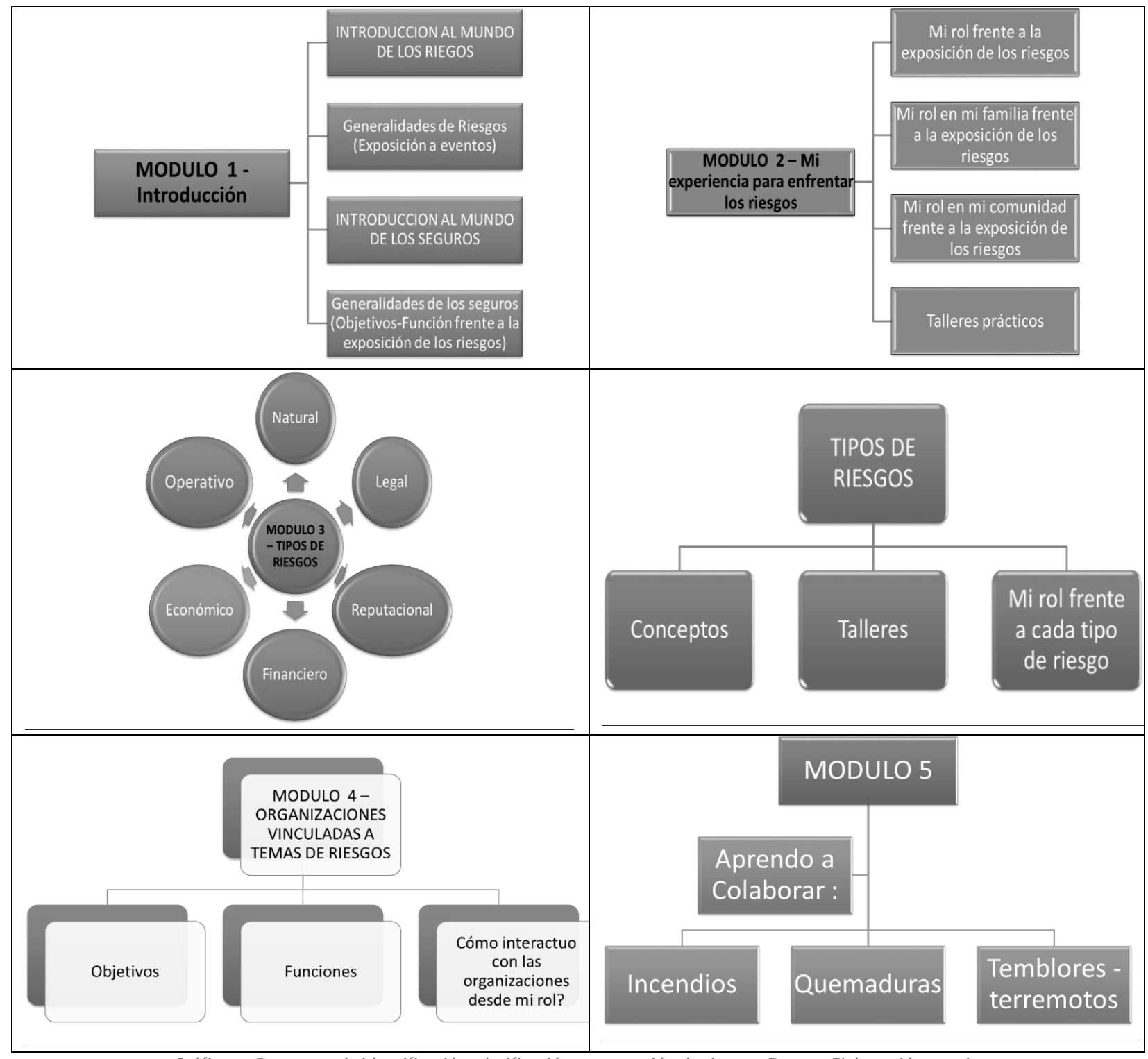

Gráfico 5. Programa de identificación, clasificación y prevención de riesgos. Fuente: Elaboración propia.

Para la implementación de estos contenidos se recomienda:

- El uso de tablas e infografías que concreten y sinteticen la información. 
- Organizar cronológica precisa y detalladamente la información.

- Especificación de la metodología relativa a una tradición epistemológica, tecnológica/disciplinar y argumentar su elección.

\section{CONCLUSIONES}

Un riesgo es un evento que afecta indistintamente a las personas con diferentes características socioeconómicas. Su comprensión es importante para entender las dinámicas del entorno cambiante en el que vivimos y que puede establecerse gracias a las respuestas aportadas por los estudiantes que voluntariamente respondieron las preguntas planteadas, para obtener los resultados enseñados en el presente trabajo sobre lo que piensan, saben y quieren jóvenes de entre los 16 y 17 años con respecto a una formación en riesgos para los grados $10^{\circ}$ y $11^{\circ}$.

Es evidente la permanente exposición a la ocurrencia de los diferentes riesgos típicos de una ciudad como Bogotá que, basados en la definición de riesgos, permite establecer la probabilidad de que vuelvan a materializarse una y otra vez, en períodos de tiempo predecibles, haciendo uso de eventos pasados, así como deducir la magnitud de su impacto en términos de indicadores tales como pérdidas humanas y económicas, partiendo especialmente de los desastres naturales. De ahí la importancia de sensibilizar sobre la presencia de cada uno de los riesgos referenciados.

Una ciudad como Bogotá que ha afrontado desde temblores hasta atentados terroristas, merece una ciudadanía informada acerca de cómo mitigar sus riesgos, reconocer las distintas alternativas que en términos de seguros existen para su protección, así como otras alternativas de tipo financiero y de colaboración del Estado colombiano, con el fin de estar preparados y de poder tomar medidas de prevención basadas en una educación a temprana edad acerca de los riesgos.

"De allí parte la necesidad de educar a la gente sobre su importancia y lo significativo del blindaje patrimonial." (Ruiz, 2017, p. 22). Lo que se pretende en un futuro, con una formación en riesgos es que el mercado asegurador crezca bajo unos cimientos sólidos de conocimientos y conciencia, donde no sean solo las personas que trabajan en seguros los que sepan sobre el tema, sino que todos los ciudadanos conozcan cómo funciona y para qué sirven, desde el entendimiento de los riesgos. "... aún el principal reto sigue siendo el conocimiento de los ciudadanos sobre la importancia de asegurar los bienes, para no lamentarse si ocurre alguna adversidad." (Nacional de Seguros, 2017, p. 1).

Esta formación no le compete exclusivamente al gremio asegurador, experto en el tema de riesgos; basados en los indicadores mostrados podemos afirmar que la responsabilidad recae también en el Estado, quien con los lineamientos que viene desarrollando para la Administración de los riesgos de desastres, sumado a esfuerzos para la protección de la vida y el patrimonio de los ciudadanos, se podrían presentar alternativas de educación que apunten a que la ciudadanía pueda asumir con responsabilidad sus propios riesgos.

La propuesta de este trabajo es iniciar con concientizar a la sociedad bogotana sobre la importancia de involucrar de manera activa a los jóvenes de educación básica secundaria, especialmente de los grados 10 y 11, además de aquellos quienes demuestren interés en aprender acerca de riesgos. Gracias a la entrevista realizada se pudo proponer un programa académico, de formación didáctica dirigida a jóvenes, que favorezca la formación en conocimientos fundamentales para la vida, basados especialmente en una educación financiera a temprana edad.

Estos contenidos presentados pueden abarcar tanto a jóvenes pertenecientes a instituciones de educación privada como pública, abordando cada una de sus necesidades en lo que a riesgos se refiere, sin hacer distinciones socioeconómicas, proponiendo medidas de autoevaluación con el fin de que el programa académico 
sea ajustado a las necesidades de la ciudad y del país, reconociendo sus efectos entre la población, especialmente al momento de medir su actitud frente al riesgo.

Una sociedad educada en riesgos podrá, con información, tomar decisiones acerca de su posible necesidad de asegurabilidad, o tomar decisiones de diferente índole en pro de preservar sus finanzas y garantizar el cubrimiento de sus necesidades básicas, aún ante los eventos más desastrosos que atenten contra su vida y la de su familia.

\section{REFERENCIAS BIBLIOGRÁFICAS}

Banca de las Oportunidade, FASECOLDA, \& Superintendencia Financiera de Colombia. (2018). Estudio de demanda de seguros. Bogotá: Puntoaparte.

CDPMIF - Comisión Distrital para la Prevención y Mitigación de Incendios Forestales. Informes de Gestión Anual 1999 al 2016.

Inundaciones en Colombia, tomado de Estudio Nacional del Agua ENA, IDEAM, 2014. Principales obras del megaproyecto de Saneamiento del Río Bogotá.

Bitácora de Emergencias, bases de datos del sistema de Información para la Gestión del Riesgo y Cambio Climático del Distrito Capital SIRE - Instituto Distrital de Gestión del Riesgo y cambio climático IDIGER.

Instituto de Hidrología, Meteorología y Estudios Ambientales (IDEAM), El Estudio Nacional del Agua (ENA), 2014.

Perfil de Desastres para Colombia, Universidad Católica de Lovaina (Bélgica), por medio de la base de datos internacional de desastres (EM-DAT), del Centro de Investigación en Epidemiología de Desastres (CRED, por sus siglas en inglés)

GEMMA: PMA (2007): Geociencias para las Comunidades Andinas. Movimientos en masa en la región andina: una guía para la evaluación de amenazas. Grupo de Estándares para Movimientos en Masa (GEMMA). Publicación internacional.

Banca de las Oportunidade, FASECOLDA, \& Superintendencia Financiera de Colombia. (2018). Estudio de demanda de seguros. Bogotá: Puntoaparte.

García M., Carlos Arturo;. (06 de julio de 2013). El Tiempo. Obtenido de eltiempo.com: https://www.eltiempo.com/archivo/documento/CMS-12915052

Grupo Inercia Valor. (11 de febrero de 2020). sectorial.co. Obtenido de https://www.sectorial.co/informativaasegurador/item/295917-\%C2\%BFc\%C3\%B3mo-est\%C3\%A1-la-cultura-del-seguro-en-colombia

Ruiz Reyes, Luis Ramón;. (s.f. de agosto de 2017). segurosyfinanzashoy.com. Obtenido de https://www.segurosyfinanzashoy.com/nueva-cultura-del-seguro-vida-latinoamerica/

Servicio de Estudios de MAPFRE. (s.f. de Septiembre de 2019). mapfreglobalrisks.com. Obtenido de https://www.mapfreglobalrisks.com/gerencia-riesgos-seguros/wp-content/uploads/2019/10/El-mercadoasegurador-latinoamericano-en-2018.pdf

Valora Analitik. (29 de agosto de 2019). valoraanalitik.com. Obtenido de https://www.valoraanalitik.com/2019/08/29/penetracion-de-seguros-en-latinoamerica-aun-es-baja-perocuenta-con-potencial-para-crecer/ 
Arana, A. (2015). La cultura del aseguramiento y la protección para nuestros asociados y sus familias. Revista Coomeva.

DUQUE E.G: Manual de geología para Ingenieros, Capitulo 16 “Movimientos Masales" -- Universidad Nacional de Colombia sede Manizales.

ESPINOSA, A., (2003). Historia Sísmica de Colombia, 1550 - 1830. Academia colombiana de Ciencias Exactas, Físicas y Naturales - Universidad del Quindio. Publicación electrónica, 315 p., Banco de Datos de Historia Sísmica de Colombia.

García M., Carlos Arturo;. (06 de julio de 2013). El Tiempo. Obtenido de eltiempo.com: https://www.eltiempo.com/archivo/documento/CMS-12915052

IDIGER (2015). Panorama general de riesgo. Soporte del Plan Distrital de Gestión de Riesgos y Cambio Climático (PDGR-CC). Bogotá.

INGEOMINAS, UNIANDES, (1997). Microzonificación Sísmica de Bogotá. Publicación especial Ingeominas. Bogotá.

Julivert, M. (1963). Observaciones sobre el Cuaternario de la Sabana de Bogotá. Boletín de Geología Universidad Industrial de Santander. No.7, pp. 52. Bucaramanga.

MONTERO J (1995): Estabilidad de taludes. Conferencia Universidad Nacional de Colombia, Manizales.

Plan Nacional de Prevención Control de incendios forestales y restauración de áreas afectadas 2012- Comisión Nacional asesora para I prevención y Mitigación de Incendios forestales

Palomino, J. (2013). Bogotá, líder en gestión de riesgos. Periódico el Espectador.

Popescu, M.E. (2001) Landslide Causal Factors And Landslide Remediatial Options Illinois Institute of Technology, Chicago, USA.

Ruiz Reyes, Luis Ramón;. (s.f. de agosto de 2017). segurosyfinanzashoy.com. Obtenido de https://www.segurosyfinanzashoy.com/nueva-cultura-del-seguro-vida-latinoamerica/

Servicio de Estudios de MAPFRE. (s.f. de Septiembre de 2019). mapfreglobalrisks.com. Obtenido de https://www.mapfreglobalrisks.com/gerencia-riesgos-seguros/wp-content/uploads/2019/10/El-mercadoasegurador-latinoamericano-en-2018.pdf

USGS (2008) Manual de derrumbes: Una guía para entender todo sobre los derrumbes. Publicación conjunta por Lynn M. Highland (USGS) y Peter Bobrowsky (GSC).

Vergara, I. (2007). Educar para fomentar la Cultura del Seguro. Revista Fasecolda. 